\title{
Predicting odor perceptual similarity from odor structure
}

\author{
Kobi Snitz , Adi Yablonka, Tali Weiss, Idan Frumin, Rehan M Khan, Noam Sobel \\ From 1st International Workshop on Odor Spaces \\ Hannover, Germany. 4-7 September 2013
}

Abstract not submitted for publication.

Published: 16 April 2014

\author{
doi:10.1186/2044-7248-3-S1-O2 \\ Cite this article as: Snitz et al:: Predicting odor perceptual similarity \\ from odor structure. Flavour 2014 3(Suppl 1):O2.
}

- Convenient online submission

- Thorough peer review

- No space constraints or color figure charges

- Immediate publication on acceptance

- Inclusion in PubMed, CAS, Scopus and Google Scholar

- Research which is freely available for redistribution

Submit your manuscript at 